\title{
A HISTÓRIA E FILOSOFIA DA CIÊNCIA NA EDUCAÇÃO BÁSICA BRASILEIRA: POR UM PROCESSO DE CONSTRUÇÃO DO CONHECIMENO CIENTÍFICO NA ESCOLA
}

\author{
LA HISTORIA Y LA FILOSOFÍA DE LA CIENCIA EN LA EDUCACIÓN BÁSICA \\ BRASILEÑA: POR UN PROCESO DE CONSTRUCCIÓN DEL CONOCIMIENTO \\ CIENTÍFICO EN LA ESCUELA
}
HISTORY AND PHILOSOPHY OF SCIENCE IN BRAZILIAN BASIC EDUCATION: BY A PROCESS OF BUILDING SCIENTIFIC KNOWLEDGE IN THE SCHOOL

\author{
Viviane Maciel Machado MAURENTE ${ }^{1}$ \\ Jorge Alberto MOLINA ${ }^{2}$ \\ Arisa Araujo da LUZ ${ }^{3}$
}

RESUMO: As relações entre as ciências, o contexto histórico de sua produção e as concepções filosóficas vigentes em uma determinada época se tornam visíveis ao considerar a história da ciência. Pois ela mostra os vínculos entre a história em sentido amplo, quer dizer, história política, econômica, cultural e social, com as próprias ciências e com a filosofia da ciência. Esse artigo busca discutir a história e filosofia da ciência na educação básica, seus limites e possibilidades. Como a educação básica vem abordando a ciência na escola; como a formação de professores está trabalhando com futuros docentes a ciência na escola; como está colocada a história e filosofia da ciência nos currículos de formação de professores e na educação básica, como as áreas conversam e compartilham da história e filosofia da ciência quando da construção do conhecimento e de saberes. Se propõe a resgatar a história e filosofia da ciência enquanto saber histórico constituído através dos tempos, bem como a evolução da ciência a partir do olhar de epistemólogos como Kunh (1971), Popper (1994), Bachelard (1996). Traz reflexões acerca das limitações da educação em ciências na educação básica e finaliza contextualizando a importância da história e filosofia da ciência estar presente nos currículos de formação de professores e da educação básica.

PALAVRAS-CHAVE: História. Filosofia. Ciência. Ensino aprendizagem. Educação básica.

${ }^{1}$ Universidade Estadual do Rio Grande do Sul (UERGS), São Luiz Gonzaga - RS - Brasil. Professora Adjunta. Atua no Curso de Pedagogia e no Mestrado Profissional em Educação. Doutorado em Educação em Ciências: Química da Vida e Saúde (UERGS). ORCID: https://orcid.org/0000-0002-3976-6594. E-mail: vivianemaurente@uergs.edu.br

${ }^{2}$ Universidade Estadual do Rio Grande do Sul (UERGS), São Luiz Gonzaga - RS - Brasil. Professor Adjunto. Atua no Curso de Pedagogia. Pesquisador na área da História e Filosofia da Ciência. Doutorado em Lógica e Filosofia da Ciência (UNICAMP). ORCID: https://orcid.org/0000-0003-0727-324X. E-mail: jorgemolina@uergs.edu.br

${ }^{3}$ Universidade Estadual do Rio Grande do Sul (UERGS), São Luiz Gonzaga - RS - Brasil. Professora Adjunta. Atua no Curso de Pedagogia e pesquisa na área da Pedagogia da Diferença. Diretora do Campus Regional IV. Doutorado em Educação (UNISINOS). ORCID: https://orcid.org/0000-0002-2285-5339. E-mail: arisaluz@uergs.edu.br 
RESUMEN: Las relaciones entre las ciencias, el contexto histórico de su producción y las concepciones filosóficas vigentes en un momento dado se hacen visibles al considerar la historia de la ciencia. Porque muestra los vínculos entre la historia en un sentido amplio, es decir, la historia política, económica, cultural y social, con las ciencias mismas y con la filosofía de la ciencia. Este artículo busca discutir la historia y la filosofia de la ciencia en la educación básica, sus límites y posibilidades. Cómo la educación básica se ha acercado a la ciencia en la escuela; cómo la formación docente está trabajando con futuros profesores de ciencias en la escuela; cómo se coloca la historia y la filosofía de la ciencia en los planes de estudio de educación docente y la educación básica; cómo las áreas hablan y comparten la historia y la filosofia de la ciencia al construir el conocimiento y el conocimiento. Proponen rescatar la historia y la filosofía de la ciencia como conocimiento histórico constituido con el tiempo, así como la evolución de la ciencia desde la perspectiva de epistemólogos como Kunh (1971), Popper (1994), Bachelard (1996). Trae reflexiones sobre las limitaciones de la educación científica en la educación básica y termina contextualizando la importancia de la historia y la filosofía de la ciencia para estar presentes en los planes de estudio de educación docente y educación básica.

PALABRAS CLAVE: Historia. Filosofía. Ciencias. Enseñanza del aprendizaje. Educación básica.

ABSTRACT: The relations between the sciences, the historical context of their production and the philosophical conceptions prevailing in a given time become visible when considering the history of science. For it shows the links between history in the broad sense, that is, political, economic, cultural and social history, with the sciences themselves and with the philosophy of science. This article seeks to discuss the history and philosophy of science in basic education, its limits and possibilities. How basic education has been addressing science in school; how teacher education is working with future teachers in science at school; how is the history and philosophy of science placed in teacher education curricula and basic education, how do the areas talk and share the history and philosophy of science in the construction of knowledge and knowledge? They propose to rescue the history and philosophy of science as historical knowledge constituted throughout the ages, as well as the evolution of science from the perspective of epistemologists such as Kunh (1971), Popper (19), Bachelard (1996). It brings reflections on the limitations of science education in basic education and concludes by contextualizing the importance of the history and philosophy of science being present in the curricula of teacher education and basic education.

KEYWORDS: History. Philosophy. Science. Teacher training. Basic education.

\section{Introdução: As ciências e sua relação com a história e a filosofia}

As relações entre as ciências, o contexto histórico de sua produção e as concepções filosóficas vigentes em uma determinada época se tornam visíveis ao considerar a história da ciência. Pois ela mostra os vínculos entre a história em sentido amplo, quer dizer, história política, econômica, cultural e social, com as próprias ciências e com a filosofia da ciência. Sabemos hoje a partir dos clássicos trabalhos de Koyré (2001) e de Kuhn (1957) que a prática

RIAEE - Revista Ibero-Americana de Estudos em Educação, Araraquara, v. 16, n. 4, p. 2379-2394, out./dez. 2021. e-ISSN: 1982-5587 
do cientista está determinada pelas concepções de mundo dominantes no tempo em que vive e pela situação histórica daquela época, ainda que ele não seja completamente ciente delas. Entendemos que supostos filosóficos estabelecem os objetos de estudo das ciências, os métodos que são admissíveis na prática científica, os critérios para a formação de hipóteses, a forma de verificá-las, a maneira de expor as ciências nos livros de texto e de ensiná-la.

Mesmo em disciplinas tão abstratas como as ciências matemáticas e aparentemente tão pouco determinadas pelo seu entorno cultural, aquelas influências podem ser verificadas. Com efeito, os critérios para reconhecer um conjunto de argumentos como uma prova matemática têm variado com as épocas. Durante muito tempo se pensou, conforme ao princípio aristotélico de incomunicabilidade dos gêneros, que uma prova geométrica não podia usar considerações aritméticas e algébricas (ARISTÓTELES, 1979, p. 44-45). Muitos séculos depois, na sua Geometria, Descartes usou nas suas demonstrações ferramentas algébricas. A justificação do seu procedimento se deu na primeira de suas Regras para a direção do espírito, quando estabeleceu a unidade de todas as ciências (tradução OLASO; ZWANCK, 1995)

Outro exemplo muito conhecido pelos historiadores da ciência é aquele da determinação da estrutura do sistema solar, nos séculos XVI e XVII. Sabemos que Ptolomeu, Copérnico, Kepler, Galileu e Tycho Brahe formaram diferentes hipóteses astronômicas. Ptolomeu e Copérnico consideravam que o movimento dos planetas devia ser explicado em termos da composição de movimentos circulares porque os dois eram dependentes da antiga ideia filosófica de que o movimento circular é o movimento perfeito, por não ter nem princípio nem fim, sendo então, aquele que corresponde a seres perfeitos como eram considerados os planetas (ANDRÉ, 1996; ANDREY et al., 2007).

Kepler teve a ousadia de quebrar essa concepção, mas não por isso esteve livre de influências filosóficas. Com efeito, a estrutura para o sistema solar proposta por ele mostra que Kepler foi guiado pela hipótese, dependente da filosofia pitagórica, de que devia haver uma correspondência entre o número de poliedros regulares e o número de planetas. Se Copérnico situou o sol como centro do sistema solar foi pela influência de ideias neoplatônicas vigentes na Renascença que se achavam representadas, entre outros autores, por Marsílio Ficíno (KUHN, 1957, p. 154). Elementos neoplatônicos e pitagóricos se encontram também na Astronomia de Kepler.

É possível determinar em detalhe a influência da situação histórica na qual vivem ou viveram os cientistas sobre seu trabalho. De acordo com Andrey et al. (2007), a medicina na Idade Média estava limitada em seu avanço pela proibição, que vinha já desde a Antiguidade 
clássica, de dissecar cadáveres humanos. Dessa forma os conhecimentos dos médicos sobre a anatomia humana se restringiam ao que poderia ser apreendido por meio da disseção de animais. $\mathrm{O}$ autor ainda explica que, naquela época, as cirurgias não eram realizadas pelo médico, e sim pelo barbeiro, um homem prático. O médico, baseado nas suas leituras dos antigos mestres da Antiguidade clássica, Hipócrates e Galeno, prescrevia quais tratamentos deviam ser realizados, incluindo entre eles a cirurgia (ANDREY et al., 2007).

O grande avanço do conhecimento médico se deu quando, no século XVII, como consequência da concepção mecanicista da Natureza e do dualismo cartesiano, o corpo humano deixou de ser visto como algo sagrado e passou a ser considerado como uma simples máquina. Conforme André (1996), encontramos todo um ambiente cultural que possibilitou essa nova concepção: os construtores de máquinas (mecânicos) ganharam naquela época prestígio social e dinheiro, a arte começou a representar o corpo humano nu, o pensamento filosófico e teológico encontrou as marcas da ação divina principalmente na alma humana e não na Natureza, sendo a alma concebida por Descartes como realidade completamente diferente do corpo. De fato, Descartes provou a existência de Deus a partir da presença da ideia de Deus na alma humana, diferentemente do que fez Santo Tomás de Aquino, máximo representante da Escolástica medieval, que pretendeu demonstrar a existência de Deus a partir da realidade do movimento na Natureza.

E, no entanto, os cientistas inovadores não estão totalmente subordinados a uma tradição, a uma determinada situação histórica e cultural de tal modo que sua liberdade de pensar esteja totalmente restringida. Eles podem, pelo contrário, enriquecer e modificar aquela tradição. Mas para apreciar suas inovações devemos ter presente o marco histórico no qual eles desenvolveram seus trabalhos. Conforme nos diz Stengers (2002, p. 12):

\begin{abstract}
A história das ciências não tem por atores seres humanos "a serviço da verdade", se essa verdade deve se definir segundo critérios que fogem à história, e sim seres humanos "a serviço da história", que têm como problema transformar a história e transformá-la de maneira tal que seus colegas, mas também aqueles que, após eles, forem escrever a história, sejam obrigados a falar de sua invenção como de uma "descoberta" que outros teriam podido fazer.
\end{abstract}

\title{
Ciências e humanidades da ciência na educação básica brasileira
}

A Educação Básica Brasileira compreende crianças e jovens dos 6 até os 18 anos de idade, perfazendo no total 12 anos de estudo. O sistema de educação pública brasileiro foi criado no final do século XIX, em uma época em que no país estava fortemente vigente o 
positivismo de Comte, que foi adotado pela elite política como ideologia modernizadora. Naquela época o país tinha-se transformado em República, deixando para traz o regime monárquico ligado aos fazendeiros escravocratas. Como é de conhecimento, o positivismo tinha uma concepção linear da evolução intelectual da Humanidade. A etapa superior dessa evolução corresponde, segundo Comte, à Ciência, que superaria a Filosofia e a Religião. A época de Comte corresponde a um período de grande desenvolvimento das ciências exatas e naturais. Também é a época da industrialização da Europa, tempo em que os positivistas pensaram que os métodos usados nas ciências naturais poderiam servir para construir uma ciência do homem e da sociedade. Foi naquela época que surgiram as ciências humanas (ANDREY et al., 2007).

Para nosso tema interessa refletir sobre a influência da ideologia positivista na formação dos profissionais da educação brasileiros, bem como sua influência nos currículos escolares. Os positivistas introduziram no Brasil as ciências físicas e naturais nas escolas primárias e secundárias. O positivismo no Brasil representou uma ruptura de um lado com a chamada cultura bacharelesca, representada pelos bacharéis em direito. Era essa uma cultura retórica e literária, alicerceada no latim jurídico e no estudo dos códigos e das diversas teorias sobre o Direito e o Estado. Por outro lado, o positivismo brasileiro se pôs também em oposição à cultura eclesiástica, baseada na Teologia católica e na Filosofia escolástica. Assim, o positivismo brasileiro se colocou em nome da ciência, e do progresso, contra os dois ramos da educação humanista, na forma tal como eles se encontravam naquela época representados no Brasil, a saber, a tradição retórico-literária e a filosófica (CHALMERS, 1993).

Como a direção da educação na nascente república ficou nas mãos de pessoas influídas pela ideologia positivista se produziu um divórcio no âmbito escolar entre a cultura científica e a cultura humanista, dentro da qual se encontra o ensino da história. Esse divórcio perdura até hoje e se mostra nos livros de texto usados para o ensino de ciências tanto no nível fundamental quanto no médio. Esses textos quase não mencionam os vínculos entre as ciências, a história e a filosofia. E quando os mencionam os fazem de uma forma simplificada.

Uma consequência da concepção positivista na educação brasileira foi que ela reforçou a ideia de que as disciplinas escolares estão isoladas uma das outras e devem ser trabalhadas dessa forma. Ainda que mais de 120 anos depois que essa concepção positivista se introduziu no Brasil, vestígios dela se encontram no âmbito escolar. Mesmo com a divisão por 4 áreas do conhecimento (área das linguagens, da matemática, das ciências humanas e ciências da natureza), ainda encontramos pouco diálogo nas áreas e entre as áreas, 
permanecendo distante a discussão da ciência na construção do conhecimento científico com vista ao desenvolvimento da cidadania dos estudantes.

\section{A História da ciência e o processo de ensino e aprendizagem das ciências na educação básica}

As concepções educativas ligadas ao positivismo têm, entre outros, estes defeitos: não conseguir entender de forma apropriada o insucesso escolar na aprendizagem das disciplinas científicas e não contribuir para tornar essa aprendizagem significativa. Ainda hoje é comum a atribuição do insucesso nas disciplinas científicas ao aluno. Ele não teria o talento para as matemáticas ou suas capacidades de atenção e observação seriam limitadas, ou não relacionaria conceitos e situações, nem perceberia semelhanças e analogias. Porém, se o professor for além, dar-se-ia conta de que muitas vezes as dificuldades apresentadas pelos alunos decorrem do fato deles estarem ligados a concepções advindas do senso comum.

Este senso comum não é só o produto de ideologias ou doutrinas científicas ultrapassadas senão também ele se alicerça na forma dos nossos sentidos perceberem o mundo e na maneira de nossa mente funcionar. O senso comum é um produto psíquico, social e cultural. Devemos ter presente que se a Humanidade demorou tanto tempo em saber que a Terra se move é pelo fato de nós não termos percebido seu movimento, diferentemente do que acontece quando estamos dentro de um carro em movimento.

A pessoa que nunca teve aulas de Física elementar tenderá a acreditar que o corpo mais pesado cai mais rápido do que o mais leve. Com certeza a maioria das pessoas acredita que uma figura tridimensional cujos lados são infinitos necessariamente tem um volume infinito, mesmo que Torricelli tenha mostrado há cerca de quatrocentos anos que esse não é sempre o caso. Muitos pensam que a baleia é um peixe, e não veem em um fóssil mais do que uma pedra. Para o leigo uma mesa é algo sólido e compacto, já para o físico e para a pessoa que domina os rudimentos dessa ciência qualquer mesa é um composto de átomos e estes não são algo compacto, não são um espaço pleno, mas incluem em grande parte o vazio.

O senso comum, fundado na nossa percepção sensorial, nos leva a acreditar que o Sol é duas ou três vezes maior do que a Lua. E, no entanto, a ciência nos diz que o diâmetro do primeiro astro é $1.391 .000 \mathrm{~km}$ e o do segundo é apenas 3474,2 km. Essas crenças, que são impostas acerca dos conhecimentos científicos ensinados pelo sistema escolar, chamamos de erros, visto que estão enraizadas na nossa linguagem e na nossa cultura. Se o aluno tem 
dificuldades em dominar certos conceitos e teorias científicas é porque a Humanidade teve as mesmas dificuldades e isso é o que mostra a história da ciência (ANDREY et al., 2007).

No século XX o epistemólogo Gaston Bachelard denominou obstáculos epistemológicos esses entraves individuais e coletivos para a construção do conhecimento científico. Trouxe para a discussão a noção de obstáculos epistemológicos como as etapas a serem ultrapassadas para a aquisição do conhecimento científico, ou seja, para passar de um conhecimento já conhecido para um novo conhecimento existem obstáculos a serem transpostos. Podemos afirmar que esses são os obstáculos que a criança no seu desenvolvimento cognitivo e a Humanidade na construção da ciência tiveram que vencer. Se o aluno demora em entender um princípio como a lei de inércia ou os conceitos de números imaginários e negativos, ou as leis de Kepler ou os vínculos evolutivos entre as diferentes espécies, é porque a Humanidade mesma tardou em chegar a esses conhecimentos

A evolução das ciências é dificultada por obstáculos epistemológicos entre os quais o senso comum, os dados perceptíveis [...]. Para conseguir superálos, são necessários atos epistemológicos: ruptura com os conhecimentos anteriores, seguidos por sua reestruturação (BACHELARD, 1996, p. 62).

Bachelard salienta a necessidade de romper com o conhecimento baseado no senso comum. Esse conhecimento é concreto, baseado na percepção sensorial, ao passo que o conhecimento científico tende à abstração. Segundo Bachelard (1996, p. 49),

[...] o ato de conhecer dá-se contra um conhecimento anterior, superando o que, no próprio espírito, é obstáculo à espiritualização [...]. Isso significa que as sucessivas contradições do passado, que se afiguram como autênticas rupturas epistemológicas, seriam as molas propulsoras do desenvolvimento do conhecimento científico. Nesse sentido, a história da ciência avançaria com base em sucessivas rupturas epistemológicas.

A história da ciência para Bachelard mostra a superação sucessiva dos obstáculos epistemológicos. Nesse processo o conhecimento é visto como um avançar de forma progressiva, aproximando-se da verdade por meio de um longo trabalho de construção e de retificação, rompendo com o saber anterior (SAITO, 2013). É dessa forma que a história da ciência deve ser apresentada nas escolas, mostrando os processos que levaram à superação dos obstáculos epistemológicos surgidos na tentativa de compreender a natureza. Assim o processo de construção do conhecimento científico torna-se mais acessível e claro não só para o aluno, mas também para o professor.

Os conhecimentos prévios do cotidiano dos alunos não devem ser vistos apenas como erros individuais senão como formas que nossa espécie tem de abordar a Natureza. Já no 
início da Idade moderna, Francis Bacon, em seu Novum Organum, dissertou sobre os obstáculos que dificultam nossa concepção de mundo. Ele os chamou de ídolos. Os ídolos da tribo decorrem da estrutura de nosso intelecto, os ídolos do foro surgem de nossa linguagem, os de teatro de doutrinas filosóficas e científicas erradas, finalmente os ídolos da caverna são erros estritamente individuais, originados na nossa educação e na nossa criação.

Segundo Nascimento e Carvalho (2004), conhecer o passado histórico e a origem do conhecimento científico pode ser um fator motivador para os estudantes, pode fazer com que os estudantes percebam que a dúvida encontrada por eles para a aprendizagem de um conceito científico foi a mesma que encontrou, em outro momento histórico, um cientista hoje reconhecido, ou seja, percebam que suas dúvidas estiveram presentes em algum momento no processo da construção desse conceito científico.

A história da ciência, segundo Solbes e Traver (2001, p. 158), pode fazer com que os estudantes:

i Conheçam melhor os aspectos da história da ciência, antes geralmente ignorados e, consequentemente, mostrar uma imagem da ciência mais completa e contextualizada;

ii Valorizem adequadamente processos internos do trabalho científico como: os problemas abordados, o papel da descoberta, a importância dos experimentos, o formalismo matemático e a evolução dos conhecimentos (crises, controvérsias e mudanças internas);

iii Valorizem adequadamente aspectos externos como: o caráter coletivo do trabalho científico, as implicações sociais da ciência.

E ainda afirmam que ela própria pode:

iv Apresentar uma imagem menos tópica da ciência e dos cientistas;

$\mathrm{v}$ Melhorar o clima da aula e a participação no processo de ensino aprendizagem.

A proposta de um ensino mais histórico se contrapõe ao ensino mecânico, cumulativo e socialmente neutro. A inclusão nos conteúdos escolares da história da ciência e da filosofia da ciência pode contribuir na proposta de metodologias de aulas mais desafiadoras e criativas. O conhecimento científico e tecnológico faz parte, hoje, do cotidiano dos seres humanos, estimulando os professores a adaptarem suas práticas educativas a essa nova realidade, com estratégias que tornem o processo de ensino e aprendizagem atrativo e desafiador para os alunos. Pôr o conhecimento ao alcance de todos, independentemente da classe social, cultura, crenças e valores é uma tarefa das escolas no século XXI.

A permanência dos currículos escolares com metodologias tradicionais, segundo Loguercio e Del Pino (2006, p. 68), proporcionam aos "alunos uma imagem deformada de como se constituem e evoluem os conceitos cientificos". E, ainda, segundo esses autores, os 
professores, também, em função das características de sua formação, em relação à construção do conhecimento científico, ao trabalho dos cientistas, aos métodos das ciências e à imagem da ciência, constroem entendimentos equivocados (LOGUERCIO; DEL PINO, 2006; MATHEWS, 1994; SOLBES; TRAVER, 2001).

Nascimento e Carvalho (2004) se apoiam em Abd-El-Khalick e Lederman (2000) para explicar que a opção pelo uso da história é uma forma de abordar a epistemologia das ciências em sala de aula, aparecendo grandemente como uma alternativa ao ensino tradicional das ciências:

Os programas devem continuar com tentativas (de melhorar as concepções dos estudantes). Elementos de história e filosofia da ciência e/ou instrução direta sobre a natureza da ciência são mais efetivos em alcançar este fim do que os que utilizam processos fechados ou não reflexivos de atividade ( $\mathrm{p}$. 667).

Pensar a ciência como produto acabado é negar as diferentes possibilidades de transformação e construção do conhecimento. É diminuir a capacidade de criação e a criatividade dos alunos na escola, é mascarar uma ciência dita como verdadeira. É não possibilitar novas descobertas e criações. A escola como responsável por transmitir os conhecimentos científicos tem condições de criar inúmeras possibilidades de se conversar sobre a ciência nos bancos escolares, incentivando a pesquisa desde a infância.

Uma disciplina de história da ciência, ou uma abordagem histórica do conhecimento científico tem um extraordinário valor pedagógico, um grande significado cultural que, associado à Filosofia da Ciência, tem uma relevante contribuição à compreensão epistemológica da construção desse conhecimento. A História e a Filosofia da Ciência podem ter um papel facilitador da alfabetização científica do cidadão (LOGUERCIO; DEL PINO, 2006, p. 68).

Se os currículos de formação de professores procurassem incorporar em suas grades curriculares componentes de Filosofia e História da Ciência, os professores poderiam discutir sobre a ciência e suas diferentes concepções, bem como sobre o conhecimento científico e seu ensino. Concepções essas que também seriam construídas pelos alunos, na escola, desde os seus primeiros anos. Nessa lógica os conhecimentos prévios seriam os indicadores para a introdução de novos conhecimentos, onde a ciência seria construída a partir da realidade vivida, dos contextos culturais, sociais e políticos.

Tendo em vista os conhecimentos anteriores como pré-requisito para a aprendizagem de conhecimentos novos, Stengers (2002) afirma que a ciência deve, como qualquer outra prática humana, ser inserida na história e que, deste ponto de vista, não pode haver 
descompromisso, nem meio-termo. Contudo, esse ideal legítimo nos permite elidir questões problema que nos remetem a indagar: por que essa inserção da história e filosofia da ciência na formação do professor não é tão tranquila? Por que os currículos escolares não conseguem dialogar com a história do conhecimento científico em suas quatro áreas do conhecimento? A contextualização histórica das disciplinas escolares paralelo ao conhecimento do conteúdo a ser aprendido poderá auxiliar a escola na formação da cidadania de seus estudantes? E, como fazer com que os estudantes enxerguem a ciência e suas relações com a sociedade, tecnologia, cultura e política, ou seja, com o mundo?

\section{A História da ciência e a construção da cidadania na escola}

Partindo das questões problema, desejamos que a escola ofereça uma educação consciente e crítica, estimulando os alunos no dia a dia a tomarem decisões e terem escolhas adequadas com a realidade vivida. Isso é um ideal da educação em muitos países. Segundo Paixão e Cachapuz (2003, p. 31) [...], a “educação em ciência deve contribuir para formar cidadãos mais cultos, mais informados e mais críticos", onde o conhecimento científico se confrontará com o conhecimento prévio do aluno, que poderá ter ou não resistências ao novo conhecimento.

Ao professor, como detentor desse conhecimento, cabe buscar estratégias para transformar o senso comum em conhecimento científico. Uma possibilidade é mostrar a ciência como uma construção humana, sujeita à influência de fatores sociais, econômicos e culturais de seu tempo (DEL PINO; STRACK, 2012). Aproximar a história da ciência da escola e do ato de ensinar é um desafio que deve ser almejado a partir de propostas pedagógicas desafiadoras, levando-se em conta o conhecimento prévio que os alunos trazem de suas experiências de vida.

Mas em que sentido a educação científica pode tornar os cidadãos mais cultos, mais informados e mais críticos? Um dos primeiros teóricos a se perguntar sobre o valor educativo da ciência foi Jean Jacques Rousseau. O sociólogo português Boaventura de Sousa Santos se refere a esse autor, ao seu célebre Discours sur les Sciences et Les Arts, segunda parte, uma dissertação escrita para um concurso organizado pela Academia de Dijon, na qual Rousseau formula várias questões. Essas perguntas colocavam em dúvida a confiança iluminista na Razão. Boaventura de Souza Santos parafraseia as questões de Rousseau da seguinte forma:

Há alguma relação entre a ciência e a virtude? Há alguma razão para substituirmos o conhecimento vulgar que temos da natureza e da vida e que 
partilhamos com os homens e mulheres na nossa sociedade pelo conhecimento científico produzido por poucos e inacessível à maioria? Contribuirá a ciência para diminuir o fosso crescente na nossa sociedade entre o que se é e o que se aparenta ser, o saber dizer e o saber fazer, entre a teoria e a prática? Perguntas simples a que Rousseau responde de modo igualmente simples, com um redondo não (SANTOS, 1987, p. 17).

O que Rousseau entendia por "virtude" é o que chamaríamos hoje excelência moral e consciência cidadã. Ele demandava se a ciência poderia contribuir ao progresso moral da Humanidade. Rousseau buscou respostas a esses questionamentos em uma época em que o paradigma científico dominante era o mecanicista, paradigma que se constitui a partir da revolução científica do século XVII e que teve sua expressão mais completa na Física de Newton. É oportuno aqui lembrar quais eram as imagens de ciência e de Natureza associadas a esse paradigma. Ao contrário da ciência aristotélica que concebia a Natureza como um grande ser vivo, o mecanicismo newtoniano a representava como uma máquina.

No período de Rousseau, de acordo com Santos (1987), a ciência não era vista como uma ferramenta de emancipação social. Reconhecia-se seu valor emancipatório individual para os membros das classes abastadas no sentido de libertá-los da superstição religiosa. De outro lado, admitia-se que a ciência poderia ser útil para o domínio e controle da Natureza, mas, por não se ter iniciado ainda o processo de industrialização da Europa esses avanços tecnológicos e suas aplicações não eram reconhecidos.

Hoje daríamos uma resposta diferente à dada por Roussau. Vislumbramos a ciência e a tecnologia como essenciais para a sociedade, por produzir diferentes vacinas para várias doenças, permitir a construção de pontes e estradas, e colocar à nossa disposição aparelhos que nos dão conforto, como geladeiras e automóveis. Mas também, a ciência possui um papel na construção dos valores nos cidadãos. Se para Rousseau a opressão vinha principalmente das instituições religiosas hoje ela vem mais do poder político e econômico, e se manifesta de formas muito mais sutis até o ponto de que não seja vista como tal.

A escola pode contribuir para a reflexão crítica dessas armadilhas impostas pelo poder político e econômico, transmitindo conhecimentos científicos necessários a fim de que o educando forme seu juízo crítico. Aqui os educadores deveriam lembrar de Descartes (2012), no livro Regras para a orientação do espírito, ao colocar como primeira regra a seguinte: "a finalidade dos estudos deve ser a de dirigir o espírito para que possa formar juízos sólidos e verdadeiros sobre todas as coisas que se lhe apresentam".

Nesse viés, entende-se que o desafio dos professores, atualmente, segundo Bizzo (2002), é reconhecer a real possibilidade de entender o conhecimento científico e a sua 
importância na formação de nossos alunos, uma vez que ele contribui efetivamente para a ampliação da capacidade de compreensão e atuação no mundo em que vivemos. Já para Chassot (2003, p. 94), “[...] não se pode mais conceber propostas para o ensino de ciências, sem incluir nos currículos componentes que estejam orientados na busca de aspectos sociais e pessoais dos estudantes. A "ciência pode ser tomada como uma forma de dar sentido ao mundo natural e tecnológico, ao mesmo tempo tem, em mente, a construção da cidadania responsável” (PAIXÃO; CACHAPUZ, 2003, p. 31).

Qual seria o papel da História da ciência dentro desta educação científica? Ela induz quem a conhece uma sã prudência no sentido de ser cauteloso e não aceitar qualquer coisa que se apresente sob as roupas da ciência como se fosse ciência exata, verificada e comprovada. Por outro lado, ela nos mostra as diferentes faces enganosas de pseudociência. Um caso típico de pseudociência é o da Astrologia, na qual tem-se uma concepção errônea do que era, até o século XVII, pois a identificamos como os horóscopos que lemos hoje nos jornais e revistas. Mas, de acordo com Andrey et al. (2007), essa ciência é algo muito mais sofisticado e complexo. E explica que Astrologia misturava ferramentas matemáticas complexas com concepções filosóficas e mágicas. Era uma fraude, mas difícil de ser reconhecida como tal. Foi apoiada por governantes ansiosos de prever o futuro dos acontecimentos políticos. Foi cultivada por pessoas que hoje reconhecemos como grandes cientistas, entre eles Ptolomeu e Kepler. Ainda que criticada duramente por intelectuais de destaque como Santo Agostinho e Pico de la Mirandola, ela sobreviveu. Só declinou, e ficou reduzida ao que é hoje, quando a concepção aristotélica do universo foi substituída pela concepção newtoniana (ANDREY et al., 2007).

Outro caso de pseudociência, no final do século XIX, é o das teorias sobre as raças humanas e sobre a superioridade de algumas raças sobre outras. Essas teorias misturavam o pré-conceito racial com as doutrinas evolucionistas baseadas na obra de Darwin e na filosofia de Spencer, sendo consideradas políticas de Estado como a de tornar branca a população brasileira mediante a imigração europeia.

Doravante, a história da ciência nos mostra o caráter provisório das teorias científicas. Elas são as melhores conjecturas que a Humanidade dispõe em um momento de sua evolução. Conjecturas bem elaboradas, mas que no futuro poderão ser consideradas parcialmente ou totalmente inadequadas. Para o século XVIII, a Física newtoniana era a encarnação da verdade, e hoje somos, porém, cientes de suas limitações. Cabe aos cursos de formação de professores discutir em seus currículos o papel da história da ciência na sociedade, na 
formação dos cidadãos, levando para os bancos escolares reflexões críticas frente à evolução da ciência nos dias de hoje e como essa ciência está presente na vida do ser humano.

\section{Conclusões: um ideal a ser alcançado}

Temos aqui defendido a necessidade da introdução da história da ciência tanto nos currículos de formação dos professores para a Educação Básica, quanto nas aulas das disciplinas escolares, apoiando-nos nas seguintes razões: a) ela permite ao professor compreender vários dos motivos que fazem o aluno não compreender suas aulas; b) ela propicia o diálogo entre os professores de diversas áreas do conhecimento, sobretudo, entre os professores vindos da área das ciências humanas e aqueles com formação nas ciências da natureza, da matemática e das linguagens; c) ela ajuda a introduzir valores que são necessários para a formação de uma consciência de cidadania; d) ela torna para o aluno significativa a aprendizagem das disciplinas científicas.

Valorizar os conhecimentos prévios dos alunos, relacionar as práticas educativas dos professores com a sociedade e a tecnologia são desafios emergentes no século XXI. Os currículos de formação de professores devem atentar a essas demandas, proporcionando ao futuro profissional da educação saberes que constituem a realidade das escolas, consequentemente das crianças e jovens.

Para que possamos nos entender enquanto cidadão que pertence a uma sociedade, que passa o maior tempo de sua vida nos bancos escolares, se faz necessário o resgaste histórico dessa sociedade, dessa educação, dos fatos científicos pertencentes a ela. E a Educação Básica é um dos espaços nobres para sua contextualização, cabendo aos professores mediarem a construção do conhecimento. Outro espaço é a formação de professores, ao prepará-los para a docência na Educação Básica.

Defendemos um diálogo permanente entre as áreas do conhecimento, um processo de educação colaborativa com olhar na formação da cidadania das crianças e jovens, onde a aprendizagem das disciplinas escolares as tornem significativas e aplicáveis na realidade vivida. Nessa perspectiva sugere-se metodologias que estimulem a problematização, projetos de pesquisa a partir de um contexto real, resgaste histórico da ciência, bem como o seu percurso até os dias de hoje.

Já os currículos de formação de professores necessitam revisitar a ciência enquanto conhecimento necessário de sua formação, trazendo os aspectos de sua história, bem como da sociedade, natureza e tecnologia, resgatando e valorizando saberes docentes que se empenhem 
a discutir a realidade, experiências e saberes de senso comum. A história da ciência possibilita o conhecimento de fatos, períodos, quebras de paradigmas, rupturas e incertezas frente aos acontecimentos da natureza. Os professores em formação precisam dialogar sobre esses aspectos a fim de levarem para suas práticas docentes esse conhecimento.

Consideramos a história da ciência um ideal a ser alcançado por todos que atuam na educação e acreditam que através dela podemos mudar a realidade, tornando nossas crianças e jovens cidadãos de sua sociedade.

\section{REFERÊNCIAS}

ABD-EL-KHALICK, F.; LEDERMAN, N. G. Improving science teachers conceptions of nature of science: a critical review of the literature. International Journal of Science Education, v. 22, n. 7, p. 665-701, 2000. DOI: 10.1080/09500690050044044

ANDRÉ, J. M. Da história das ciências à filosofia da ciência. Revista Filosófica de Coimbra, v. 5, n. 10, 1996.

ANDREY, M. A. et al. Para compreender a ciência: uma perspectiva histórica. Rio de Janeiro: Editora Garamond, 2007.

ARISTÓTELES. Les seconds analytiques. Trad. Tricot J. Paris: Vrin., 1979.

BACHELARD, G. A formação do espírito científico: contribuição para uma psicanálise do conhecimento. Trad. Estela dos Santos Abreu. Rio de Janeiro: Contraponto, 1996.

BACON, F. Novum organum ou verdadeiras indicações acerca da interpretação da natureza. São Paulo: Nova Cultural, 1988.

BIZZO, N. Ciências: fácil ou difícil? Palavras do professor. 2. ed. São Paulo: Editora Ática, 2002.

CHALMERS, A. F. O que é ciência afinal? São Paulo: Editora brasiliense, 1993.

CHASSOT, A Alfabetização científica: uma possibilidade para a inclusão social. Revista Brasileira de Educação, Campinas, n. 22, 2003. DOI: 10.1590/S1413-24782003000100009

DEL PINO, J.; STRACK, R. O desafio da cientificidade na sala de aula. Revista Pátio, Conhecimento Científico no Ensino Médio, n. 12, ano IV, mar./maio 2012.

DESCARTES, R. Regras para a orientação do espírito. São Paulo: Editora WMF Martins Fontes, 2012.

KOYRÉ, A. Do mundo fechado ao universo infinito. 4. ed. Rio de Janeiro: Forense universitária, 2001.

KUNH, T. A revolução copernicana. Trad. Marília Costa Fontes. Lisboa: Edições 70, 1957.

RIAEE - Revista Ibero-Americana de Estudos em Educação, Araraquara, v. 16, n. 4, p. 2379-2394, out./dez. 2021. e-ISSN: 1982-5587 
KUNH, T. La estrctura de las revoluciones científicas. Trad. Agustin Contin. México: Fondo de cultura económica, 1971.

LOGUERCIO, R.; DEL PINO, J. C. Contribuições da história e da filosofia da ciência para a construção do conhecimento científico em contextos de formação profissional da química. Acta Scientiae, Canoas, v. 8, n.1, p. 67-77, jan./jun. 2006. Disponível em: http://hdl.handle.net/10183/143201. Acesso em: 10 ago. 2020.

MATHEWS, M. R. História, filosofia e ensino de ciências: a tendência atual de reaproximação. Caderno Catarinense de Ensino de Física, Florianópolis, v. 12, n. 3, p. 164214, dez. 1994. Disponível em: https://periodicos.ufsc.br/index.php/fisica/article/view/7084. Acesso em: 10 ago. 2020.

NASCIMENTO, V. B.; CARVALHO, A. M. P. A Natureza do conhecimento científico e o ensino de ciências. 2015. Disponível em:

http://fep.if.usp.br/ profis/arquivos/vienpec/CR2/p452.pdf. Acesso em: 1 jan. 2019.

PAIXÃO, F; CACHAPUZ, A. Mudanças na prática de ensino da química pela formação dos professores em história e filosofia das ciências. Química nova na Escola: pesquisa no Ensino de Química, São Paulo, n. 18, p. 31-36, nov. 2003. Disponível em:

http://www.educadores.diaadia.pr.gov.br/arquivos/File/2010/artigos_teses/quimica/mud_prat ens_form_profe_hist_qnesc_out_2003.pdf. Acesso em: 10 ago. 2020.

SAITO, F. "Continuidade" e "Descontinuidade": o processo da construção do conhecimento científico na história da ciência. Revista da Faeeba - Educação e Contemporaneidade, Salvador, v. 22, n. 39, p. 183-194, jan./jun. 2013. Disponível em:

https://www.revistas.uneb.br/index.php/faeeba/article/view/338. Acesso em: 10 ago. 2020.

SANTOS, B. S. Um discurso sobre as ciências. Edições Afrontamentos. Porto Colecção. Portugal: Histórias e Ideias, 1987.

SOLBES, J. E TRAVER, M. Resultados obtenidos introduciendo historia de la ciencia em las classes de física y quimica: mejora de la imagem de la ciencia y desarrollo de actitudes positivas. Enseñanza de las ciencias: revista de investigación y experiencias didácticas, v. 19, n. 1, p. 151-162, 2001.

STENGERS, I. A invenção das ciências modernas. Trad. Max Altman. São Paulo: Editora 34, 2002. 


\section{Como referenciar este artigo}

MAURENTE, V. M. M.; MOLINA, J. A.; LUZ, A. A. A história e filosofia da ciência na educação básica brasileira: por um processo de construção do conhecimento científico na escola. Revista Ibero-Americana de Estudos em Educação, Araraquara, v. 16, n. 4, p. 2379-2394, out./dez. 2021. https://doi.org/10.21723/riaee.v16i4.14072 e-ISSN: $\quad$ 1982-5587. DOI:

Submetido em: 20/07/2021

Revisões requeridas em: 17/08/2021

Aprovado em: 19/09/2021

Publicado em: 21/10/2021 